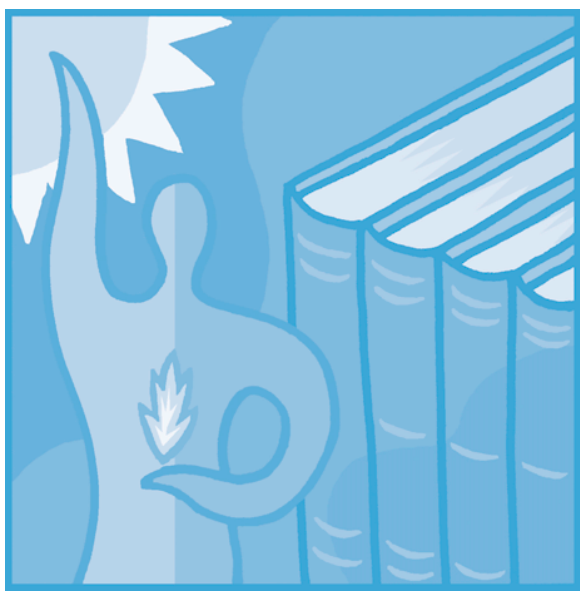

\title{
Prevention and Preparedness
}

\section{Core Competencies for Injury and Violence Prevention}

| Thomas Songer, PhD, MPH, Shelli Stephens-Stidham, MPA, Corinne Peek-Asa, PhD, Ingrid Bou-Saada, MA, MPH, Wanda Hunter, MPH, Kristen Lindemer, MPH, and Carol Runyan, PhD for the National Training Initiative for Injury and Violence Prevention

Efforts to reduce the burden of injury and violence require a workforce that is knowledgeable and skilled in prevention. However, there has been no systematic process to ensure that professionals possess the necessary competencies.

To address this deficiency, we developed a set of core competencies for public health practitioners in injury and violence prevention programs. The core competencies address domains including public health significance, data, the design and implementation of prevention activities, evaluation, program management, communication, stimulating change, and continuing education. Specific learning objectives establish goals for training in each domain.

The competencies assist in efforts to reduce the burden of injury and violence and can provide benchmarks against which to assess progress in professional capacity for injury and violence prevention. (Am $J$ Public Health. 2009;99:600606. doi:10.2105/AJPH.2008. 137331)

\section{INJURY AND VIOLENCE REMAIN} significant public health issues. Road traffic crashes, homicides, and suicides are consistently among the leading causes of death in the United States, particularly for those aged 1 to 44 years. ${ }^{1,2}$ Unintentional injuries and violence account for the largest proportion (18.5\%) of years of potential life lost before age 65 years. ${ }^{1}$ Nonfatal traumatic injuries and violence, including youth and family violence, also have serious short- and longterm physical, psychological, and emotional consequences at the individual, family, and community levels. ${ }^{3}$ For the year 2000, the economic impact of injuries in the United States was estimated at $\$ 406$ billion. ${ }^{4}$

Current efforts to reduce the burden of injury and violence are often viewed as inadequate. Collectively, injury and violence prevention efforts in health departments are low in scale and resources compared with activities to reduce the major chronic and infectious diseases. One factor underlying this observation is the now well-recognized lack of infrastructure for injury and violence prevention in public health practice. Three major reports over the past 2 decades have pointed to this poor infrastructure and the need to train a workforce for effective efforts in reducing injuries and violence. ${ }^{5-7}$
Several projects that pertain to workforce training recently have begun. The Advisory Committee on Injury Prevention and Control Working Group on Injury Control and Infrastructure Enhancement, for example, has identified a set of recommendations for strengthening the field. ${ }^{8}$ Several core competency sets have also been developed to promote training and development in specific fields of injury and violence prevention, including highway safety, ${ }^{9}$ youth violence in emergency department settings, ${ }^{10}$ construction work zone safety, ${ }^{11}$ and safety of health care professionals from patient violence. ${ }^{12}$ Nine hundred individuals have also received core instruction in violence prevention as part of the Prevent Violence Through Education, Networking, and Technical Assistance (PREVENT) program. ${ }^{13}$ These training efforts, though, are reaching and affecting public health professionals involved in violence and injury prevention in a fragmented fashion. No systematic process yet exists to address the needs of these professionals.

The State and Territorial Injury Prevention Directors Association (STIPDA) and the Society for the Advancement of Violence and Injury Research have been leading an initiative to address this shortcoming. The primary objective of this collaboration has been to identify, develop, and promote a common understanding of the essential skills and knowledge necessary for individuals to excel as violence- and injury-prevention professionals in public health practice. We report on the competency set identified to meet this objective.

\section{DEVELOPING THE CORE COMPETENCIES}

Identifying fundamental competencies to guide future infrastructure development is not unique to the injury and violence field. Core competencies were first discussed by Prahalad and Hamel with respect to business practice in the 1990s. ${ }^{14}$ Their central notion was that, over time, companies develop key areas of expertise that are distinctive to that company and critical to its longterm growth.

In the time since the seminal work of Prahalad and Hamel, core competencies have become an integral part of many business and nonbusiness practices. Core competency sets have been identified throughout the public health field, 


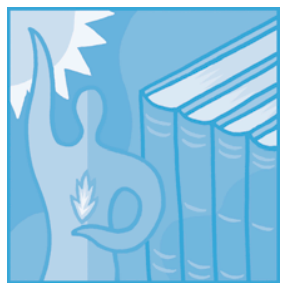

including the widely publicized core competencies for public health practice. ${ }^{15}$ Competency sets also exist in very specific areas of injury and violence fields. However, unintentional injuries and violence encompass a broad range of causes, intentions, and outcomes. Public health and other wide-scale programs designed to reduce the burden of injuries and violence need professionals with a broad array of skills and knowledge. At present, there is no comprehensive and systematic way to ensure that those who work to prevent injury and violence possess the competencies necessary to be effective.

In 2000, STIPDA and the National Association of Injury Control Research Centers formed the
Joint Committee on Infrastructure Development. (The National Association of Injury Control Research Centers formally changed its name in 2005 to the Society for the Advancement of Violence and Injury Research [SAVIR]. The collaboration outlined in this work is now known as the SAVIRSTIPDA Joint Committee on Infrastructure Development.) This joint effort is unique in that it brings together the expertise of members from disparate disciplines: state-based public health injury and violence prevention practitioners and academic-based educators. The National Training Initiative for Injury and Violence Prevention (NTI) was built from this collaboration to focus on specific training efforts.

\section{Identifying Essential}

Knowledge and Skills

One issue quickly recognized by the NTI was the lack of a consensus in the field regarding what skills and knowledge are distinctive and critical to success in injury and violence prevention practice. Thus, one of the first activities of the NTI was to develop a protocol for identifying the essential knowledge and skills, or core competencies. The process began by focusing discussion on the question, what do injury and violence prevention professionals need to know to be effective? This is a fundamental question that has been discussed and debated by practitioners and researchers for decades.
To answer this question, a working group of NTI members discussed what made existing practices in the field effective, reviewed existing competency sets in several disciplines, reviewed existing curricula in injury prevention, and identified and implemented needs assessments of practicing professionals. The range of material reviewed by the group is listed in the box on this page.

\section{Drafting Specific}

Competencies and Learning Objectives

In drafting the core competencies, the NTI working group quickly faced 2 strategic issues: identifying the intended audience for the competencies and determining the level of specificity to

Materials Examined to Draft the Core Competencies for Injury and Violence Prevention: National Training Initiative for Injury and Violence Prevention

Relevant Competency Sets Reviewed

- Core competencies for public health professionals, Council on Linkages Between Academia and Public Health Practice. ${ }^{15}$

- The Public Health Workforce: An Agenda for the 21st Century, US Department of Health and Human Services. ${ }^{16}$

- Core competencies for injury prevention, Indian Health Service.

- Core competencies for effective practice, Southern California Developing Center for Youth Violence Prevention. ${ }^{10}$

- Competencies for maternal and child health, Association of Teachers in Maternal and Child Health. ${ }^{17}$

Objective Materials Reviewed

- State and Technical Assessment Team Review Guide, STIPDA. ${ }^{18}$

- Course objectives, Hopkins Summer Institute on Injury Prevention.

- Canadian injury prevention and control curriculum, Canadian Collaborative Centres for Injury Prevention. ${ }^{19}$

- TEACH-VIP-international injury prevention curriculum, World Health Organization. ${ }^{20}$

Needs Assessments Reviewed

- Training needs assessment, Education Development Center, 1989.

- Pre-Vincent training needs assessment, University of North Carolina Injury Prevention Research Center, 1996.

- Core capacity survey, STIPDA, 2000.

- Education needs assessment, Canadian Collaborative Centres for Injury Prevention, 2000. ${ }^{21}$

- Training survey of health departments, NAICRC-STIPDA Joint Committee on Infrastructure Development, 2001.

- Survey of Safe USA participants, NAICRC-STIPDA Joint Committee on Infrastructure Development, 2001.

Note. STIPDA = State and Territorial Injury Prevention Directors Association; NAICRC=National Association of Injury Control Research Centers. The National Association of Injury Control Research Centers formally changed its name in 2005 to the Society for the Advancement of Violence and Injury Research (SAVIR). The collaboration outlined in this work is now known as the SAVIR-STIPDA Joint Committee on Infrastructure Development. 


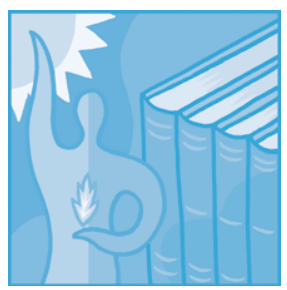

apply to the competencies. Injury and violence prevention is a broad field encompassing different disciplines, including public health, law enforcement, emergency medical services, occupational health, highway and traffic safety, and others. The diversity of practices and approaches makes it difficult to create a single competency set that is appropriately relevant for all practitioners. As a result, the competencies outlined here were developed with a primary focus on public health practitioners.

Several discussions ensued regarding the level of specificity to apply to the competencies. By consensus, it was determined that the identified relevant skills and knowledge should be specific to injury and violence programmatic needs. The working group,

though, also recognized that there are areas of overlap between public health practice and injuryprevention practice and that some essential skills, such as building and evaluating programs, are generic to both types of activities. To avoid repeating the public health competencies for public health practice, in areas of overlapping essential skills, the working group outlined and emphasized the salient features of these skills as they are applied in injury- and violenceprevention practice.

Next, the working group drafted 8 core competencies and their related learning objectives. The learning objectives were written to provide future trainers and educators with measurable goals for the assessment of learning. The drafted competencies and learning objectives were then presented to the full NTI committee for review and comment. A revised document based upon the full committee comments was then approved by majority vote, and a process for external review of the document was identified.

\section{Expert Panel Review}

A panel of experts in violenceand injury-prevention practice and research performed an external review of the draft competencies and learning objectives. Nominations for individuals to serve on the panel were solicited from NTI committee members and the 6 participating organizations in the NTI (the Centers for Disease Control and Prevention, National Center for Injury Prevention and Control; Indian Health Service; Health Resources and Services Administration, Maternal and Child Health Bureau; Children's Safety Network; STIPDA; and National Association of Injury Control Research Centers). A total of 179 individuals were nominated, of whom 62 were selected for the panel. Thirty members were from the participating organizations in NTI. An additional 30 members were selected from external organizations, and 2 individuals were selected to serve as technical experts in the competency development process. Selection criteria for all panel members also considered the need to balance the distribution of expertise across different levels of research and practice, different areas of injury and violence prevention expertise, and different levels of experience in the competency concentrations, including data, program management, program evaluation, policy development, and media relations.

Of the 62 individuals invited to serve on the expert panel, 53 (85.5\%) accepted the request to comment. They were mailed a draft copy of the competencies and asked to provide overall general comments and specific thoughts for each of the individual competencies. Responses were received from 52 individuals. The characteristics of these individuals are outlined in Table 1. Overall, the respondents averaged 14.3 years of experience as an injury- or violence-prevention professional. Many individuals (47\%) had experience in more than 1 workplace. Altogether, the group had meaningful experience in federal agencies, universities, local and state health departments, and nonprofit organizations. More than half of the group had served as a manager or supervisor at some point in their tenure.

The complement of comments from the panel members was wide-ranging. To consider the comments, the working group developed a structured template to standardize the presentation and analysis by competency area. Further, the group conducted a qualitative review to identify

\begin{tabular}{lr} 
TABLE 1-Characteristics of the Expert Panel Respondents \\
(N= 52) for Core Competencies for Injury and Violence \\
Prevention: National Training Initiative for Injury and Violence \\
Prevention & $\%$ \\
\hline \multicolumn{2}{c}{ Characteristic } \\
\hline Area of expertise & \\
Unintentional injury & 38.6 \\
Intentional injury or violence & 9.1 \\
Both unintentional and intentional injury & 52.3 \\
Place of work (experience>1 y) & \\
Federal agency & 47.9 \\
University & 47.9 \\
Private or nonprofit organization & 33.3 \\
State health department & 31.3 \\
Hospital or health care organization & 31.3 \\
Local health department & 18.8 \\
Position (responsibility for $>1$ y) & \\
Manager or supervisor & 64.6 \\
Health educator & 37.5 \\
Coalition leader or program coordinator & 37.5 \\
University educator & 31.3 \\
Epidemiologist & 29.2 \\
Other public health position & 25.0 \\
Physician & 16.7
\end{tabular}

Note. Totals do not add to $100 \%$ because of multiple responses from individuals. 


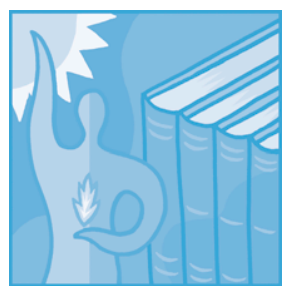

common themes in the comments. Major themes arising from the expert panel comments included the use of unclear terminology or jargon, questions about which audience the competencies were directed to, unclear competency objectives, missing competencies or missing objectives, and redundant or overlapping objectives.

The committee considered all comments in the revision process. First, the document was edited to incorporate the consistent use of well-defined terms and to remove jargon. The working group also revised the learning objectives for clarity and to reduce redundancy. Some panel members felt that the elements of collaboration and partnership, communication, and cultural competency were missing in the draft competency set. To address this, the NTI working group integrated these issues into the learning objectives of the existing competencies rather than adding additional competencies. The intent of this decision was to avoid redundancy with the public health core competencies and to reinforce how these general skills apply to specific injury and violence practices.

Next, the committee readdressed issues related to the most appropriate primary audience for the competencies. Some panel members felt that the competencies were too centered within public health, whereas other members expressed the view that the objectives were too advanced for some practitioners. To address the first perspective, the consensus decision of the working group was that the audience should remain public health practitioners, because of the difficulty in developing specific skills sets for each audience with an interest in injury or violence prevention. However, the working group did revise the competency set to change wording to allow for the potential application of the competencies to all types of practitioners, such as those in law enforcement or emergency response.

One major revision involved the draft competency on dissemination of information to policymakers and leaders. Many panel members interpreted this competency as addressing advocacy, but not the need for injury- and violence-prevention practitioners to have communication skills. These are varied, yet complementary skills. In response, the working group recognized the need to distinguish between these skills, and it revised the prior competency to pertain to communication skills. Further, it added a new competency to address advocacy and the ability to stimulate change in the community.

The working group also dealt with concerns from the panel members that the competency objectives were too advanced for some practitioners. The working group reaffirmed that the underlying purpose of the competencies was to identify where the prevention field should be in terms of knowledge and skills. It was recognized that not all individuals will be at the identified competency level at this time. It was also recognized that different job positions require different levels of skills. Thus, it was decided to develop a second document that assigns a level of proficiency to each learning objective based upon the type of position of the individual (e.g., manager, supervisor, field worker). This proficiency document is currently available online. $^{22}$

\section{Public Comment}

After due discussion of the expert panel comments, the core competency document was revised and then opened to the public for review and comment. The public comment period was open for 6 weeks in September and October 2004. Invitations to comment were sent by e-mail to a large group of injury prevention professionals in the field, different from the expert panel, who were then asked to distribute the invitation to their colleagues. The request to comment was also posted on a Web site. ${ }^{22}$ The respondents represented 32 distinct agencies and organizations across the spectrum of practice from the public, private, academic, advocacy, and acute care perspectives. A protocol similar to that used to address the expert panel comments was used to address the public comments. On consideration of the comments received, final revisions were made to the competencies and to each learning objective.

\section{THE COMPETENCIES}

Nine essential competencies for injury and violence prevention were identified by the NTI working group. Each competency also has a detailed list of learning objectives. ${ }^{22}$ The first 8 competencies describe general and foundational skills that are needed regardless of the specific area of injury or violence prevention in which a public health professional practices. The competencies cover fundamentals of injury and violence occurrence and prevention, the use of data in general and specific to programs, and the design and implementation of prevention activities. They also involve the evaluation of prevention activities, program management, communication, advocacy, and maintenance of competency.

The competencies are (1) describe and explain injury and violence as a major social and health problem; (2) access, interpret, use, and present injury and violence data; (3) design and implement injury- or violence-prevention activities; (4) evaluate injury- or violence-prevention activities; (5) build and manage an injury- or violence-prevention program; (6) disseminate information related to injury or violence prevention to the community, other professionals, key policymakers, and leaders through diverse communication networks; (7) stimulate change related to injury or violence prevention through policy, enforcement, advocacy, and education; (8) maintain and further develop competency as an injuryor violence-prevention professional; and (9) demonstrate the knowledge, skills, and best practices necessary to address at least 1 specific injury or violence topic (e.g., motor vehicle occupant injury, intimate partner violence, fire and burns, suicide, drowning, child injury) and be able to serve as a resource to convey knowledge, skill, and best practices to others regarding that area 


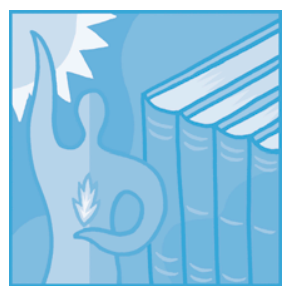

Describe and Explain Injury and Violence as a Social and Health Problem

This competency is the ability of an individual to understand the basics of injury and violence. Specific learning objectives focus on the definition of unintentional injury and intentional violence, the mechanisms surrounding their occurrence, how such events are preventable, and where injury and violence stand as a significant public health issue. Other identified objectives include an understanding of disparities in injury and violence, risk factors, how conceptual models are useful in the area, and the importance of collaboration for prevention activities. Proficiency in this competency will enable an individual to explain why and how injury and violence are preventable and how they should be prioritized in terms of funding with other leading health problems.

Access, Interpret, Use, and Present Injury and Violence Data

Specific learning objectives for this data-based competency include the ability to identify data sources for injury and violence circumstances, the strengths and weaknesses of existing surveillance and classification systems, the difference between qualitative and quantitative data in injury scenarios, and the use of data for policy, program planning, evaluation, and advocacy. Proficiency in this competency will enable an individual to understand where to get appropriate data and how to interpret it and use it to develop prevention activities.
Design and Implement Injuryor Violence-Prevention

\section{Activities}

Individuals should be able to describe and understand how to develop specific prevention initiatives, implement them, and maintain them. Important components include identifying resources for prevention efforts, identifying and explaining the role of stakeholders in these activities, understanding the spectrum of prevention activities (individual, institutional, community, etc.), and understanding the role of conceptual models in identifying prevention opportunities. Other important issues include identifying different types of interventions (e.g., passive, active) and their use in comprehensive programs, elements of an implementation plan, and the influence of cultural and other factors on prevention efforts. Proficiency in this competency will enable an individual to develop effective injury- or violence-prevention programs.

\section{Evaluate Injury- or Violence-}

\section{Prevention Activities}

Evaluation of injury- or violence-prevention activities is often lacking in current programs. This competency was designed to address this shortcoming. Important elements within this competency include understanding why evaluation of programs is needed, how to incorporate evaluation into existing and new activities, the differing types of evaluation processes, and elements of communication of evaluation results. Competent individuals should also be able to identify partners in evaluation activities, understand barriers to evaluation, and be able to develop an evaluation plan. Proficiency in this competency will enable an individual to design or identify appropriate evaluation measures for an injuryor violence-prevention program.

Build and Manage an Injuryor Violence-Prevention

\section{Program}

Professionals with the responsibility of overseeing programs should be capable managers. Important management elements for injury- or violence-prevention programs include using partners in developing program goals, understanding strategic planning, having the ability to identify funding sources, and writing proposals. Additional components should include being skilled in budgeting, recognizing strengths and limitations in programs, identifying leveraging opportunities, and using performance standards. Proficiency in this competency will enable an individual to sustain an injury- or violence-prevention program.

\section{Disseminate Information Through Diverse}

\section{Communication Networks}

Practitioners should be able to demonstrate competency in designing and delivering prevention messages, in preparing presentation documents, and in media, public, and political relations. Proficiency in this competency will enable an individual to communicate injury- or violence-prevention messages to appropriate audiences.
Stimulate Change Through

Policy, Enforcement, Advocacy, and Education

Fundamental objectives to this competency include the ability to develop a marketing plan for the promotion of prevention activities and an understanding of the differences between policy, education, lobbying, and advocacy. Individuals should recognize what current laws, policies, and regulations work, and where gaps exist in these areas. Partnering and recognition of the role of allies and opponents in policy and advocacy are also needed. Proficiency in this competency will enable an individual to identify appropriate methods to effect safe behavior.

\section{Maintain and Develop}

Competency as a Professional

This competency addresses the need for professionals to stay current with new developments in research and practice. Identifying new information in journals and electronic resources is one element of this process, as is understanding the role of key professional organizations in providing new information and being able to locate training resources. Proficiency in this competency will enable an individual to identify appropriate continuing-education opportunities for injury- or violence-prevention programming.

\section{Demonstrate Competency in an Injury- or Violence- \\ Prevention Topic \\ The final competency addresses a specific topic area in injury or violence prevention and the ability of an individual to understand the dynamics of the topic area and}




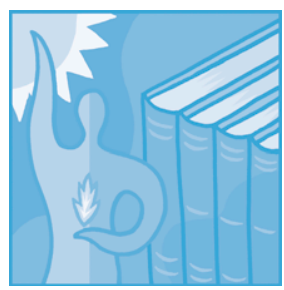

the best practices for its prevention. This last competency was designed for individuals working in specific programs or on specific projects. For specific injury or violence topics, an individual should be able to describe the causes and characteristics underlying them, what major data sources exist, what populations are at risk, who the primary stakeholders are in the area, major risk and protective factors, and what best practices exist for prevention activities. Proficiency in this competency will enable an individual to become an expert in a particular topic area in injury or violence prevention.

\section{DISCUSSION}

We have delineated the array of knowledge and skills that enable or enhance the ability of public health professionals in injury and violence prevention to practice successfully. These competencies have been developed through an extensive review of existing needs and practice and the consideration of several other competency sets. The competencies represent one of the first comprehensive standards for training and assessment for public health professionals interested in broad-based initiatives for injury and violence prevention.

The primary purpose of the competencies and their measurable objectives is to provide the public health professional with a standard set of skills for practice in injury- or violence-prevention efforts. The NTI envisions that this competency set will begin the process of development and implementation of a systematic training effort in the field and, ultimately, the enhancement of the infrastructure necessary to practice injury and violence prevention effectively.

As an example of this potential, the competencies provide a framework to guide the development of a variety of training opportunities and curricula. The PREVENT project used the core competencies to guide its training programs for more than 900 violence-prevention practitioners. ${ }^{13}$ Many more professionals in health departments, state agencies, local organizations, and community coalitions might also benefit from the use of the core competencies in this regard. The competencies can also be useful for guiding teaching efforts in academic centers, where many future prevention professionals obtain their knowledge and skills. It is also important to point out that curriculum-based training is not the only means to achieve competency. ${ }^{23}$ Several of these competencies can be acquired through additional work experience that incorporates the objectives of the competencies and complements the current practice of the individual.

The core competencies have alternate uses in workplace settings. They can be used, for example, in self-assessment exercises, needs assessments, and performance evaluations. The competencies also identify a broad benchmark of where an organization should be. In this setting, it is not expected that every individual should be an expert in all of the competencies to effectively carry out their jobs. ${ }^{24}$ It is important, however, that an organization have a collection of staff that collectively possesses the mix of skills required to best serve injury and violence prevention in its setting. ${ }^{25}$

The core competencies for injury and violence prevention intersect and overlap, in part, with other existing competencies developed for practicing professionals. For example, competencies regarding data, program development, evaluation, management, policy, and communication skills are fundamentally similar to the skills broadly needed for public health practice. ${ }^{15}$ The injury- and violence-prevention competencies, though, expand upon the public health competencies by delving into how and why injuryand violence-prevention practices relate to these concepts. This overlap was an intended consequence in the development of the competencies, because it is recognized that professionals may change programs or positions over time, both moving into and away from injury- or violence-prevention positions. Many objectives in the injury- and violence-prevention competency set, however, are independent of the public health competencies because they relate to practices unique to the injury- and violence-prevention field.

Although these carefully developed core competencies are an important step toward developing infrastructure for injury and violence prevention, it is essential to note that these competencies are not static. As science and practice evolve and injury and violence patterns change, the competencies will require regular review and periodic revision. In addition, although the skill sets are envisioned as basic and universal, those in settings outside public health practice should be careful to consider how the specific components of the competencies apply in their practice and make adaptations accordingly.

Coupled with high-quality, research-based training and consistent implementation of best practices, the core competencies serve as an important step toward addressing the enormous infrastructure gap in the field of injury and violence prevention, and ultimately may assist in the effort to reduce the burden of injury. As progress is made, the core competencies can also help to establish benchmarks against which to assess progress and identify continuing challenges.

\section{About the Authors}

Thomas Songer is with the Center for Injury Research and Control, Department of Epidemiology, Graduate School of Public Health, University of Pittsburgh, PA. At the time of the study, Shelli Stephens-Stidham was with the Injury Control Division, Oklahoma State Department of Health, Oklahoma City. Corinne Peek-Asa is with the Department of Occupational and Environmental Health, College of Public Health, University of Iowa, Iowa City. Ingrid Bou-Saada is with the Injury and Violence Prevention Branch, Division of Public Health, North Carolina Department of Health and Human Services, Raleigh. At the time of the study, Wanda Hunter was with the Injury Prevention Research Center and Department of Social Medicine, University of North Carolina, Chapel Hill.

Kristen Lindemer was with the State and Territorial Injury Prevention Directors Association, Atlanta, GA. Carol Runyan is with the Injury Prevention Research Center and the Department of Health Behavior and Health Education, University of North Carolina. Chapel Hill.

Requests for reprints should be sent to T.J. Songer, Center for Injury Research and Control, University of Pittsburgh, PARKV 203, 3520 Forbes Ave, Pittsburgh, PA 15261 (e-mail: tjs@pitt.edu).

This article was accepted July 19, 2008 


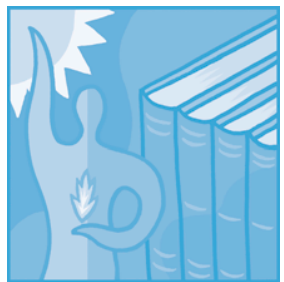

\section{Author Contributions}

$\mathrm{T}$. Songer chaired the committee that developed the competencies; drafted competencies 2, 8, and 9; and led the writing of the article. S. Stephens-Stidham was a member of the competency development committee and drafted competencies 3 and 9. C. Peek-Asa was a member of the competency development committee and drafted competencies 4 and 9. I. Bou-Saada was an invited guest of the competency committee and drafted competencies 6,7 , and 9. W. Hunter was a member of the competency development committee, wrote the first draft of the competencies, and drafted competency 5 . K. Lindemer was a member of the competency development committee and drafted competency 1. C. Runyan cochairs and administers the National

Training Initiative, was principal investigator of the grants supporting this work and reviewed drafts of the competencies. The National Training Initiative originated the notion to develop the competencies collectively as a group. All authors helped to conceptualize ideas, interpret comments, and review drafts of the article.

\section{Acknowledgments}

This work was supported by monetary funds from the Maternal and Child Health Bureau at the Health Resources and Services Administration, the National Center for Injury Prevention and Control at the Centers for Disease Control and Prevention, the State and Territorial Injury Prevention Directors Association, and the Society for the Advancement of Violence and Injury Research. In kind support was also provided by other organizations, including the Indian Health Service, National Highway Traffic Safety

Administration at the Department of Transportation, and the Children's Safety Network through the time and contributions of committee members from these groups.

The authors developed the competencies in this work as part of the National Training Initiative for Injury and Violence Prevention. This work group was formed through the collaborative efforts of the State and Territorial Injury Prevention Directors Association and the Society for the Advancement of Violence and Injury Research. The authors acknowledge the following expert panel members for their review, input, and comments on the first draft of the core competencies: Barbara Alberson, Marilena Amoni, Paul Amoroso, Meri-K Appy, James Belloni, Larry
Berger, Christine Branche, Stephanie Bryn, Larry Cohen, Lisa Cohen Barrios, Harold Cully, Luann D'Ambrosio, Alan Dellapenna Jr, Marci Diamond, Jim Enders, Eugenia Eng, Lois Fingerhut, Leroy Frazier, Andrea Gielen, David Grossman, Anara Guard, Chris Hanna, Stephen Hargarten, Roger Harrell, Janet Holden, Janie Hutcherson, Lynn Jenkins, Murray Katcher, Art Kellerman, Marc Kolman, Alan Korn, Diana Kuklinski, Maureen Lichtveld, Evelyn Lyons, Sue Mallonee, Christine Miara, Angela Mickalide, Lenora Olson, Lloyd Potter, Janet Saul, Ellen Schmidt, David Sleet, Lorann Stallones, Federico Vaca, Maria Vegega, Andrés Villaveces, Rick Waxweiler, Hank Weiss, Barak Wolff, Xan Young, Janice Yuwiler, and Ronda Zakocs.

The administrative and intellectual efforts of Theresa Cruz, Mariana Garrettson, Carol Gunther-Mohr, J'Ingrid Mathis, and Emily van Schenkhof were integral to the development and revision of the competencies. A special thank you is due to these individuals for their commitment to the project. The authors acknowledge and thank the following members of the Nationa Training Initiative for Injury and Violence Prevention for their review of the competencies: Marilena Amoni, Nancy Bill, Stephanie Bryn, Theresa Cruz, Lynda Doll, Carolyn Fowler, Deborah French, Julie Gibbs-Long, Carol Gunther-Mohr, Susan Hardman, Alex Kelter, Lloyd Potter, Julie Ross, Ellen Schmidt, Kelly Taylor, Maria Vegega, Amber Williams, and David Zane. The authors also acknowledge the individuals who provided comments on the core competencies when drafts of the competencies were open to the public. Their thoughts and views were helpful in compiling this work.

\section{Human Participant Protection}

No protocol approval was needed for this study.

\section{References}

1. Centers for Disease Control and Prevention, National Center for Injury Prevention and Control. Web-based Injury Statistics Query and Reporting System (WISQARS) [online database]. Available at: http://www.cdc.gov/ncipc/ wisqars. Accessed July 24, 2006.

2. Peden M, McGee K, Krug E. Injury; A Leading Cause of the Global Burden of Disease, 2000. Geneva, Switzerland: World Health Organization; 2002

3. Krug EG, Dahlberg LL, Mercy JA, Zwi AB, Lozano R. World Report on
Violence and Health. Geneva, Switzerland: World Health Organization; 2002.

4. Finkelstein EA, Corso PS, Miller TR Incidence and Economic Burden of Injuries in the United States. New York, NY: Oxford University Press; 2006.

5. Institute of Medicine. Reducing the Burden of Injury - Advancing Prevention and Treatment. Washington, DC: National Academy Press; 1999.

6. National Committee for Injury Prevention and Control. Injury Prevention: Meeting the Challenge. New York, NY: Oxford University Press; 1989.

7. National Research Council and Institute of Medicine. Injury in America: A Continuing Public Health Problem. Washington, DC: National Academy Press; 1985.

8. Definition of injury and violence prevention and control infrastructure. Atlanta, GA: Advisory Committee on Injury Prevention and Control Working Group on Injury Control and Infrastructure Enhancement; 2004

9. Transportation Research Board Joint Subcommittee on Safety Workforce Development. Core competencies for highway safety professionals. Washington, DC: Transportation Research Board; 2006. NCHRP Research Results Digest 302.

10. Denninghoff KR, KnoxL, Cunningham R, Partain S. Emergency medicine: competencies for youth violence prevention and control. Acad Emerg Med. 2002;9 947-956.

11. Transportation Curriculum Coordination Council. Safety \& Work Zone Competency Matrices. Washington, DC: National Highway Institute, US Dept of Transportation. Available at: http:// www.nhi.fhwa.dot.gov/tccc/ matrix05.htm. Accessed September 30, 2007.

12. Morton PG. An evolution in interdisciplinary competencies to prevent and manage patient violence. J Nurses Staff Dev. 2002:18:41-47.

13. Runyan CW, Gunther-Mohr C, Orton S, Umble K, Martin SL, CoyneBeasley TPREVENT: a program of the National Training Initiative on Injury and Violence Prevention. Am J Prev Med 2005;29:252-258.

14. Prahalad CK, Hamel G. The core competence of the corporation. Harv Bus Rev. 1990;68:79-91.
15. Public Health Foundation, Council on Linkages Between Academia and Public Health Practice. Core competencies for public health professionals. June 1999. Available at: http://www. trainingfinder.org/competencies/ list_nolevels.htm. Accessed September 30, 2007.

16. The Public Health Workforce: An Agenda for the 21st Century. Washington, DC: Office of Disease Prevention and Health Promotion, US Dept of Health and Human Services; 1997.

17. Association of Teachers in Maternal and Child Health. Competencies for maternal and child health. February 2001. Available at: http://www.atmch.org/ documents/mchcomps.pdf. Accessed September 10, 2008

18. The State and Territorial Assessment Team Review Guide. Atlanta, GA: State and Territorial Injury Prevention Directors Association; 2001.

19. Canadian Collaborative Centres for Injury Prevention and Control. Canadian injury prevention and control curriculum, final report. 2003. Available at: http:// www.canadianinjurycurriculum.ca/ documents/FinalReportCIPCCpublic. pdf. Accessed September 10, 2008.

20. TEACH-VIP, User's Manual Geneva, Switzerland: World Health Organization; 2005

21. Belton KL. Educational needs of injury control practitioners in Canada. Edmonton, Alberta: Department of Educational Policy Studies, University of Alberta; 2000.

22. National Training Initiative for Injury and Violence Prevention. Core competencies for injury and violence prevention. Available at: http://www. injuryed.org. Accessed August 23, 2008.

23. Columbia University School of Nursing, Center for Health Policy, Association of Teachers of Preventive Medicine. Competency-to-curriculum tool kit: developing curricula for public health workers. August 2004. Available at: http://www.atpm.org/publications/ Compt_to_Curric_Toolkit.pdf. Accessed September 30, 2007.

24. Gallon M, Stillman HM, Coates D Putting core competency thinking into practice. Res Technol Manage. 1995; 38:20-29.

25. Coyne KP, Hall JD, Clifford PG. Is your core competence a mirage? McKinsey Q. 1997;15:40-55. 